\title{
The Mortality Burden of Idiopathic Pulmonary Fibrosis in the United Kingdom
}

Authors: Vidya Navaratnam ${ }^{1,2,3}$ and Richard B Hubbard ${ }^{1}$

1) Division of Epidemiology and Public Health, School of Medicine, University of Nottingham, UK

2) NIHR Nottingham BRC Respiratory Theme, University of Nottingham, UK

3) Child Health Division, Menzies School of Health Research, Darwin, Australia

\section{Correspondence to:}

Dr Vidya Navaratnam

Nottingham Respiratory Research Unit,

Clinical Sciences Building, Nottingham City Hospital

Hucknall Road

Nottingham NG5 1PB

Vidya.navaratnam@nottingham.ac.uk

Keywords: interstitial lung disease, idiopathic pulmonary fibrosis, clinical epidemiology, mortality rates

Funding: VN is funded by a National Institute for Health Research (NIHR) Academic Clinical Lecturership

Disclosure: The authors declare no conflicts of interest 


\section{The Mortality Burden of Idiopathic Pulmonary Fibrosis in the United Kingdom}

\section{To the Editor,}

We have previously demonstrated that mortality from idiopathic pulmonary fibrosis (IPF) is on the rise in the UK (1) and globally.(2) Although numerous clinical trials, genetic and metabolomics studies have provided insight, large epidemiological studies on disease burden remains limited. This is particularly important now that therapeutic options for IPF are available. Despite its limitations, registered deaths from IPF are a pragmatic and validated(3) way of assessing and providing reliable estimates of disease burden in terms of mortality. The aim of our study was to provide up to date IPF mortality rate estimates and changes to trends in the UK.

\section{Methods}

Data source

We used routine mortality data from England and Wales obtained from the Office of National Statistics (ONS) (4) which is derived from registered death certificates and coded for the underlying cause of death.(5) The accuracy of coding of underlying cause of deaths is high.(6)

We used the term IPF clinical syndrome (IPF-CS) $(1,7)$ when using routinely collected clinical data, to acknowledge the difficulty in demonstrating that our study population meets ATS/ERS diagnostic criteria. (8)

\section{Statistical analysis}

We obtained annual number of deaths from IPF-CS stratified by age and sex for the years 1979 to 2016. During our study period, deaths were coded using different International Classification of Diseases (ICD) codes; from 1979 to 2000 ICD-9 codes 515 (post inflammatory fibrosis) and 516.3 (idiopathic fibrosing alveolitis) were used and from 2001 onwards it was ICD-10 code J84.1 (idiopathic pulmonary fibrosis). We extracted general population estimates for the same period. All 
data were grouped into 5-6 year periods, but without combining the different ICD codes, and 5 year age groups over the age of 55 .

Crude mortality rates stratified by age, sex and calendar period were estimated. We used direct standardization to calculate age-standardized mortality rates, standardized to the 2016 population of England and Wales. We performed a sub-analysis of the two different ICD-9 codes for IPF-CS (ICD9 code 515 and ICD-9 code 516.3). Poisson regression was used to estimate mortality rate ratios, adjusting for age and sex. We explored effect modification between trends in annual mortality rates with age and sex. Likelihood ratio tests were used for hypothesis testing. Stata v15 (StataCorp, College Station, TX) was used for all statistical analyses.

\section{Results}

A total of 82,702 deaths were attributed to IPF-CS in England and Wales from 1979 to 2016 . The overall age-standardized mortality rate for this period was 4.68 per 100,000 person-years (95\% Confidence Interval [Cl] 4.64 to 4.71). Age-standardized mortality rates increased from $1.66(95 \% \mathrm{Cl}$ 1.54 to 1.79 ) in 1979 to 8.29 ( $95 \% \mathrm{Cl} 8.06$ to 8.53 ) per 100,000 person-years in 2016 (see Figure 1 ). The annual increase in the number of IPF-CS deaths, after adjusting for age and sex was approximately 5\% (Rate Ratio [RR] 1.050, 95\% Cl 1.049 to $1.051 ; \mathrm{p}<0.001$ ). Age-standardized mortality rates were higher in men and the elderly (See Table 1). There was also strong evidence of effect modification by age $(p<0.001)$ and sex $(p<0.001)$. The increase in annual mortality rates was highest amongst men (RR per year $1.052,95 \% \mathrm{Cl} 1.051$ to 1.053 ) and over $85 \mathrm{~s}$ (RR per year 1.094, $95 \% \mathrm{Cl} 1.092$ to 1.096$)$. 


\section{Sub-analysis of ICD-9 codes}

From 1979 to 2000 there were 12,989 deaths from post-inflammatory fibrosis (ICD-9 code 515) and 16,989 deaths from idiopathic fibrosing alveolitis (ICD-9 code 516.3). The age-standardized mortality rates for both ICD-9 codes increased during this period. For post-inflammatory fibrosis, the agestandardized mortality rate increased from $0.92(95 \% \mathrm{Cl} 0.88$ to 0.97$)$ per 100,000 person-years in the 1979 to 1983 calendar period to 1.77 (95\% Cl 1.72 to 1.82 ) per 100,000 person-years in the 1995 to 2000 calendar period. Age-standardized mortality rates for idiopathic fibrosing alveolitis increased from $0.88(95 \% \mathrm{Cl} 0.84$ to 0.92$)$ to 2.41 (2.35 to 2.47$)$ per 100,000 person-years for the same calendar periods. Yearly mortality increased by $4.4 \%$ (RR $1.044,95 \% \mathrm{Cl} 1.041$ to 1.047 ) for postinflammatory fibrosis and $6.3 \%$ (RR $1.063,95 \% \mathrm{Cl} 1.060$ to 1.066 ) for idiopathic fibrosing alveolitis, after controlling for age and sex.

Figure 1: Age-standardized mortality rates for idiopathic pulmonary fibrosis clinical syndrome (IPF-

CS) in England and Wales from 1979 to 2016.

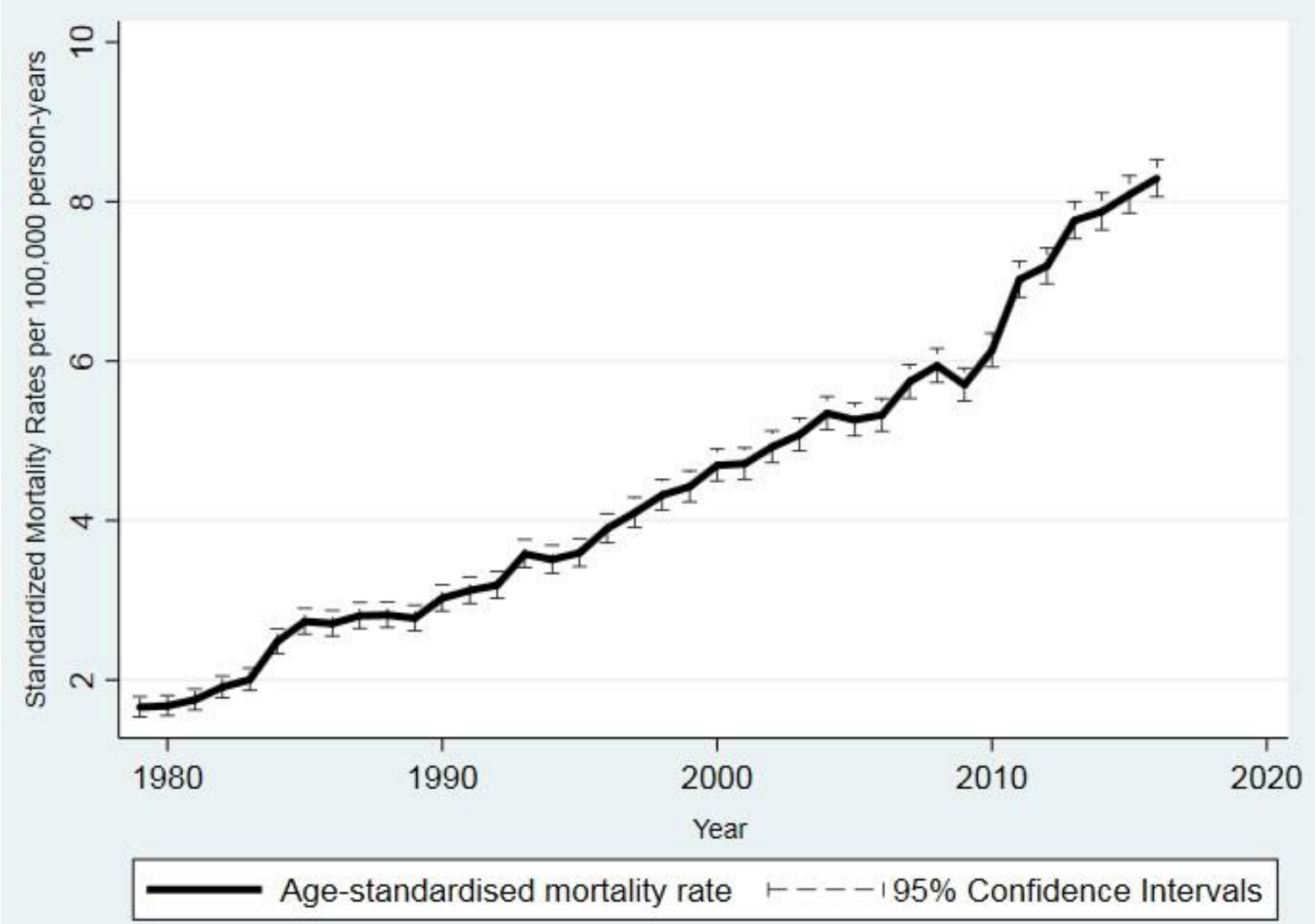


Table 1: Age-standardized mortality rates and mortality rate ratios of deaths from idiopathic pulmonary fibrosis clinical syndrome

\begin{tabular}{|c|c|c|c|c|c|}
\hline & $\begin{array}{l}\text { Number } \\
\text { of deaths }\end{array}$ & $\begin{array}{l}\text { Person- } \\
\text { years } \\
\text { (million) }\end{array}$ & $\begin{array}{l}\text { Crude mortality rate } \\
\text { per } 100,000 \text { person- } \\
\text { years }(95 \% \mathrm{Cl})\end{array}$ & $\begin{array}{l}\text { Age- standardized } \\
\text { mortality rate per } \\
100,000 \text { person - } \\
\text { years }(95 \% \mathrm{Cl})\end{array}$ & $\begin{array}{c}\text { Adjusted } \\
\text { mortality rate } \\
\text { ratio }(95 \% \mathrm{Cl})^{*}\end{array}$ \\
\hline \multicolumn{6}{|l|}{$\begin{array}{c}\text { Calendar } \\
\text { period }\end{array}$} \\
\hline \multicolumn{6}{|l|}{$I C D-9$} \\
\hline 1979-1983 & 3858 & 248 & $1.56(1.51-1.61)$ & $1.81(1.75-1.86)$ & 1.00 \\
\hline $1984-1988$ & 5888 & 250 & $2.36(2.30-2.42)$ & $2.71(2.64-2.78)$ & $\begin{array}{c}1.53(1.47- \\
1.59)\end{array}$ \\
\hline $1989-1994$ & 8640 & 305 & $2.84(2.78-2.90)$ & $3.21(31.4-3.28)$ & $\begin{array}{c}1.87(1.80- \\
1.94)\end{array}$ \\
\hline $1995-2000$ & 11577 & 310 & $3.73(3.67-3.80)$ & $4.18(4.10-4.25)$ & $\begin{array}{c}2.50(2.41- \\
2.59)\end{array}$ \\
\hline \multicolumn{6}{|l|}{ ICD-10 } \\
\hline 2001-2005 & 12197 & 265 & 4.61 (4.53-4.69) & $5.07(4.98-5.16)$ & $\begin{array}{c}3.16(3.05- \\
3.28)\end{array}$ \\
\hline $2006-2010$ & 14677 & 274 & $5.35(5.27-5.44)$ & $5.77(5.68-5.87)$ & $\begin{array}{c}3.80(3.67- \\
3.94)\end{array}$ \\
\hline 2011-2016 & 25865 & 343 & $7.53(7.44-7.63)$ & $7.71(7.62-7.81)$ & $\begin{array}{c}5.59(5.40- \\
5.78)\end{array}$ \\
\hline \multicolumn{6}{|l|}{ Sex } \\
\hline Male & 50912 & 975 & $5.22(5.18-5.27)$ & $7.41(7.34-7.48)$ & $\begin{array}{c}2.03(1.99- \\
2.05)\end{array}$ \\
\hline Female & 31790 & 1020 & $3.12(3.08-3.15)$ & $2.99(2.96-3.02)$ & 1.00 \\
\hline \multicolumn{6}{|l|}{$\begin{array}{l}\text { Age group } \\
\text { (years) }\end{array}$} \\
\hline$<54$ & 2499 & 1460 & $0.17(0.16-0.18)$ & $0.17(0.16-0.18)$ & $\begin{array}{c}0.002(0.001- \\
0.003)\end{array}$ \\
\hline $55-59$ & 2599 & 113 & $2.30(2.21-2.39)$ & $2.30(2.21-2.39)$ & $\begin{array}{c}0.26(0.25- \\
0.28) \\
\end{array}$ \\
\hline $60-64$ & 4952 & 105 & $4.71(4.58-4.85)$ & $4.71(4.59-4.84)$ & $\begin{array}{c}0.58(0.56- \\
0.60)\end{array}$ \\
\hline $65-69$ & 8837 & 95.3 & $9.27(9.08-9.47)$ & $9.27(9.08-9.47)$ & 1.00 \\
\hline $70-74$ & 13294 & 81 & $16.41(16.13-16.69)$ & $\begin{array}{c}16.41(16.13- \\
16.69) \\
\end{array}$ & $\begin{array}{c}1.93(1.87- \\
1.98) \\
\end{array}$ \\
\hline $75-79$ & 17030 & 64.4 & $26.45(26.05-26.84)$ & $\begin{array}{c}26.45(26.05- \\
26.84) \\
\end{array}$ & $\begin{array}{c}3.31(3.23- \\
3.40)\end{array}$ \\
\hline $80-84$ & 16541 & 44.2 & $37.45(36.88-38.02)$ & $\begin{array}{c}37.45(36.88- \\
38.02) \\
\end{array}$ & $\begin{array}{c}4.38(4.27- \\
4.49)\end{array}$ \\
\hline$\geq 85$ & 16950 & 35.5 & $47.78(47.06-48.50)$ & $\begin{array}{c}47.78(47.06- \\
48.50)\end{array}$ & $\begin{array}{c}4.83(4.71- \\
4.95)\end{array}$ \\
\hline
\end{tabular}




\section{Discussion}

This study demonstrates that mortality from IPF-CS continues to rise by $5 \%$ per year after accounting for an ageing population. We found a marked increase in IPF-CS deaths from 2010 onwards, with IPF-CS mortality in 2016 being 51\% higher than 2010. Sub-analysis of the ICD-9 codes showed that age-standardized mortality rates increased for both codes. Registered deaths were highest in men and the elderly, which is consistent with previous studies. $(1,2)$ Based on these findings we estimate that approximately 5,500 people die from IPF-CS in the UK each year.

One strength of our study is the large number of registered deaths and long study period, which enabled us to estimate precise changes to mortality trends and stratify our results by sex, age and calendar period. We were also able to explore if the annual increase in mortality was modified by age or sex. A possible limitation is the validity of diagnosis of IPF. However, previous studies have demonstrated a high diagnostic accuracy for death certification of lung fibrosis. $(2,3,9)$ Furthermore, we recently showed that only two-thirds of people with IPF have it recorded as their underlying cause of death and $80 \%$ had it mentioned anywhere on their death certificate (2) suggesting that our results are an under-estimate of the mortality burden and incidence of IPF in the UK. We were not able to evaluate how changes from ICD-9 to ICD-10 coding impacted mortality trends. Data from the ONS suggest that the number of deaths assigned to the respiratory chapter as a whole decreased by $22 \%$ as a result of the introduction of ICD-10 codes, largely driven by the decrease in number of deaths assigned to pneumonia.(10) It is possible that this may have resulted in further underestimating the actual number of IPF-CS related deaths.

These findings are consistent with our work demonstrating a progressive rise in IPF mortality in the UK. $(1,2,11)$ Increased case ascertainment could be a contributing factor to the trends seen, but it is also possible that the true incidence of IPF has continued to increase. If the marked increase in number of deaths is purely due to increased disease recognition, there is no evidence that ascertainment is complete, and continued upward trends in mortality are likely to be seen. 
In summary, IPF-CS now accounts for almost 7\% of all respiratory deaths in the UK (4) and carries the same mortality burden as liver, bladder and intracranial malignancies. Despite increasing research investment, it remains an important cause of respiratory mortality and a growing public health problem.

\section{(1050 words)}

\section{References}

1. Navaratnam V, Fleming KM, West J, Smith CJ, Jenkins RG, Fogarty A, Hubbard RB. The rising incidence of idiopathic pulmonary fibrosis in the U.K. Thorax 2011; 66: 462-467.

2. Hutchinson JP, McKeever TM, Fogarty AW, Navaratnam V, Hubbard RB. Increasing global mortality from idiopathic pulmonary fibrosis in the twenty-first century. Ann Am Thorac Soc 2014; 11: 1176-1185.

3. Johnston I, Britton J, Kinnear W, Logan R. Rising mortality from cryptogenic fibrosing alveolitis. BMJ 1990; 301: 1017-1021.

4. Office for National Statistics:

https://www.ons.gov.uk/peoplepopulationandcommunity/birthsdeathsandmarriages/death s\#datasets [Accessed 7/2/2019].

5. Office for National Statistics. Mortality Statistics in England and Wales QMI. Last updated July 2018 [Accessed 5/2/2019]:

https://www.ons.gov.uk/peoplepopulationandcommunity/birthsdeathsandmarriages/death $\mathrm{s} /$ methodologies/mortalitystatisticsinenglandandwalesqmi.

6. Maclaughlin Jennifer and Wells Claudia. Death Certification Reform: A Case Study on the Potential Impact on Mortality Statistics, England and Wales. Statistical Bulletin, 2012. Office for National Statistics

7. Navaratnam V, Fogarty AW, Glendening R, McKeever T, Hubbard RB. The increasing secondary care burden of idiopathic pulmonary fibrosis: hospital admission trends in England from 1998 to 2010. Chest 2013; 143: 1078-1084.

8. Raghu G, Remy-Jardin M, Myers JL, Richeldi L, Ryerson CJ, Lederer DJ, Behr J, Cottin V, Danoff SK, Morell F, Flaherty KR, Wells A, Martinez FJ, Azuma A, Bice TJ, Bouros D, Brown KK, Collard HR, Duggal A, Galvin L, Inoue Y, Jenkins RG, Johkoh T, Kazerooni EA, Kitaichi M, Knight SL, Mansour G, Nicholson AG, Pipavath SNJ, Buendia-Roldan I, Selman M, Travis WD, Walsh S, Wilson KC, American Thoracic Society ERSJRS, Latin American Thoracic S. Diagnosis of Idiopathic Pulmonary Fibrosis. An Official ATS/ERS/JRS/ALAT Clinical Practice Guideline. American journal of respiratory and critical care medicine 2018; 198: e44-e68.

9. Coultas DB, Hughes MP. Accuracy of mortality data for interstitial lung diseases in New Mexico, USA. Thorax 1996; 51: 717-720.

10. Brock A, Griffiths $C$, Rooney $C$. The impact of introducing ICD-10 on analysis of respiratory mortality trends in England and Wales. Health statistics quarterly 2006: 9-17.

11. Hubbard R, Johnston I, Coultas DB, Britton J. Mortality rates from cryptogenic fibrosing alveolitis in seven countries. Thorax 1996; 51: 711-716. 
Author Contributions VN and RBH conceived and designed the study. VN prepared and analyzed the data. VN and RBH were involved in the interpretation of the data and in writing or revising the manuscript before submission. VN takes responsibility for the integrity of the work in this manuscript and is the guarantor of the manuscript.

Acknowledgments: The authors thank Joe West for extracting and providing the data used in the study. 